\title{
Dermatosis en los deportistas
}

\author{
Marianne Kolbach R, María Laura Cossio T, M. Luisa Sáenz \\ de Santa María P, Néstor Carreño 0 , Claudia de la Cruz F, \\ Ximena Fajre W.
}

\section{Sport dermatoses}

Sports practice has become a part of modern life. As a result, the association of dermatoses with sports increases continuously. Proper diagnosis and treatment of these skin lesions requires familiarity with their characteristics clinical presentations. This article reviews the cutaneous manifestations of traumatic and environmental injuries, infections, and exacerbation of preexisting dermatoses (Rev Méd Chile 2008; 136: 249-55).

(Key words: Athletic injuries; Dermatitis; Skin diseases, infectious)

Recibido el 28 de noviembre, 2006. Aceptado el 8 de mayo, 2007.

Unidad Docente Asociada de Dermatología, Pontificia Universidad Católica de Chile, Santiago, Chile.

$\mathrm{D}$ ebido al incremento de la actividad deportiva, la consulta por lesiones cutáneas secundarias al deporte es cada vez más frecuente. Éstas pueden corresponder a lesiones de tipo traumático, infecciosas o inflamatorias, así como también lesiones asociadas específicamente al deporte y al medio ambiente donde se practica.

\section{LESIONES TRAUMÁTICAS}

Son frecuentes en zonas de roce y contacto cutáneo, ya sea por acción del ambiente, implementos deportivos o por la ropa requerida para cada disciplina. Es frecuente el compromiso de los pies, especialmente por equipamiento deportivo inadecuado ${ }^{1}$.

Ampollas por fricción. Frecuentes en los pies, producidas por roce y presión repetitiva, que

Correspondencia a: Dra. Marianne Kolbach R. U.D.A. Dermatología, Centro Médico San Joaquín, Pontificia Universidad Católica de Chile. Avda. Vicuña Mackenna 4686, Macul, Santiago. Fax: 56-2-5529974.

E mail: mkolbach@vtr.net genera separación de capas intraepidérmicas o de la lámina lúcida a nivel de la unión dermoepidérmica (Figura 1). La humedad, calor y calzado inapropiado son predisponentes. La prevención consiste en utilizar calcetines de acrílico u otra fibra sintética, que disminuyen fricción y humedad, y zapatillas adecuadas según tipo de depor$t^{1,2}$. Un estudio doble ciego demostró que el uso de cloruro de aluminio al 20\%, 3 días antes de una langa escalada, disminuye la formación de ampollas en los pies, comparado con placebo, pero se

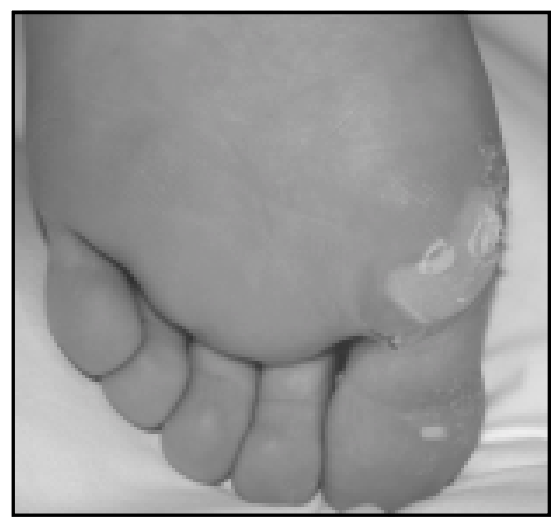

Figura 1. Ampolla por fricción en pie de corredor. 
asocia a mayor irritación ${ }^{3}$. No debe desprenderse el techo de la ampolla; sólo debe drenarse el líquido y dejar que cure espontáneamente.

Callosidades. Ocurren en áreas de roce, generalmente donde hubo una ampolla. Son indoloras, y muchos deportistas las consideran una ventaja porque evitan la formación de ampollas (Figura 2). Al remover la lesión con bisturí, no se observan hemorragias pericapilares (características de las verrugas). La prevención consiste en el uso de calzado adecuado y almohadillas para pies. Pueden removerse con abrasivos, o con aplicación regular de ácido salicílico en crema ${ }^{1,2}$.

Abrasiones. Secundarias a trauma agudo que produce denudación de la epidermis, quedando expuesta la dermis, con un sangrado puntiforme comespondiente a las arteriolas de la demis (Figura 3). El tratamiento consiste en lavar con solución salina isotónica y

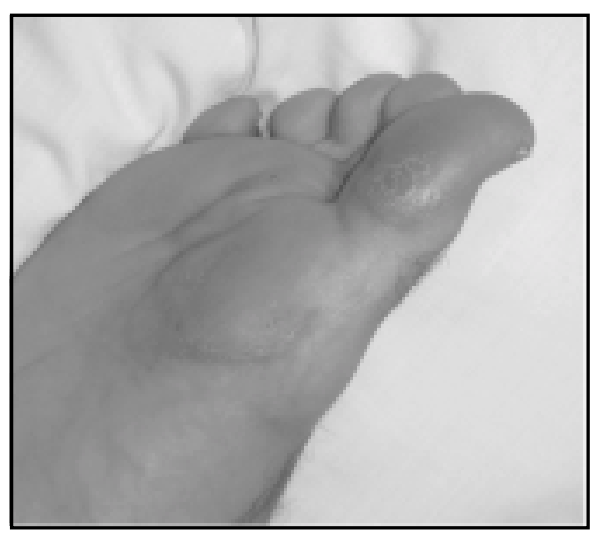

Figura 2. Callosidades en pie de futbolista.

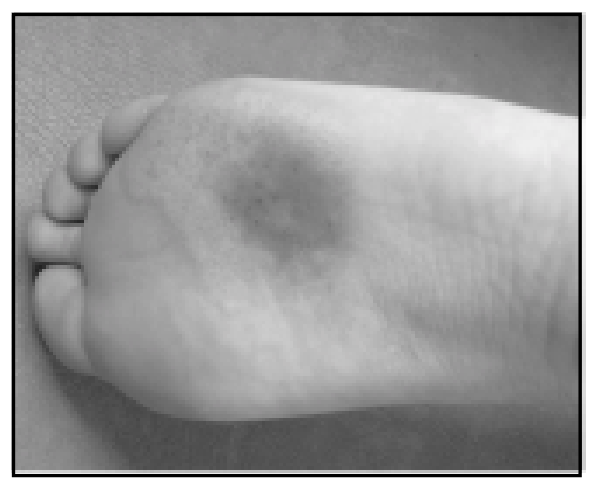

Figura 3. Trauma local con sangrado puntiforme de la dermis en pie de bailarina. aplicar ungüento con antibiótico, cubriendo con tela seca. En abrasiones más grandes pueden usarse parches de hidrocoloide semioclusivos ${ }^{4}$.

Onicocriptosis. Aunque es una patología común en todo tipo de pacientes, en los deportistas puede afectar su desempeño. La principal causa es el calzado no adecuado, que hace que los bordes laterales de las uñas penetren la dermis produciendo una reacción inflamatoria a cuerpo extraño. El tratamiento es el mismo en deportistas que en otros pacientes ${ }^{1,2}$.

Talón negro. Son petequias horizontales en el borde del talón, generalmente asintomáticas. Corresponden a hemorragias intraepidérmicas e intracorneales producidas por trauma local en deportistas que realizan partidas y paradas bruscas, como tenistas y basquetbolistas. La palma negra es similar, y ocurre en levantadores de pesas, gimnastas, golfistas, tenistas y escaladores. Estas lesiones desaparecen espontáneamente en 2 a 3 semanas con reposo, aunque pueden removerse con bisturi ${ }^{1,2}$.

Pápulas piezogénicas. Múltiples pápulas dolorosas, de 2 a $5 \mathrm{~mm}$, en superficies lateral y medial del talón. Corresponden a herniación de grasa subepidérmica hacia la dermis y son frecuentes en maratonistas, especialmente mujeres, llegando a limitar el deporte por dolor. El tratamiento quirúrgico no da buenos resultados, pero las almohadillas en los talones pueden aliviar los síntomas ${ }^{1,2}$.

Dedos del tenista. Hemorragias subungueales dolorosas, frecuentes en primer y segundo ortejo, acompañadas de distrofia ungueal, especialmente onicolisis. Se observan en corredores, esquiadores, escaladores y deportistas que realicen un deslizamiento repetitivo del pie hacia anterior o una dorsiflexión de los ortejos, chocando con la zapatilla (Figura 4). Como prevención es fundamental el uso de zapatillas adecuadas, con suficiente espacio para la dorsiflexión del pie. Se debe tomar una biopsia ante la sospecha de melanoma maligno ${ }^{1,2}$.

Pezones del corredor. Después de carreras largas, debido al roce con ropa de fibras duras como el nylon, aparecen en los pezones de hombres y mujeres, erosiones y fisuras dolorosas, que pueden sangrar. El tratamiento consiste en aplicación 


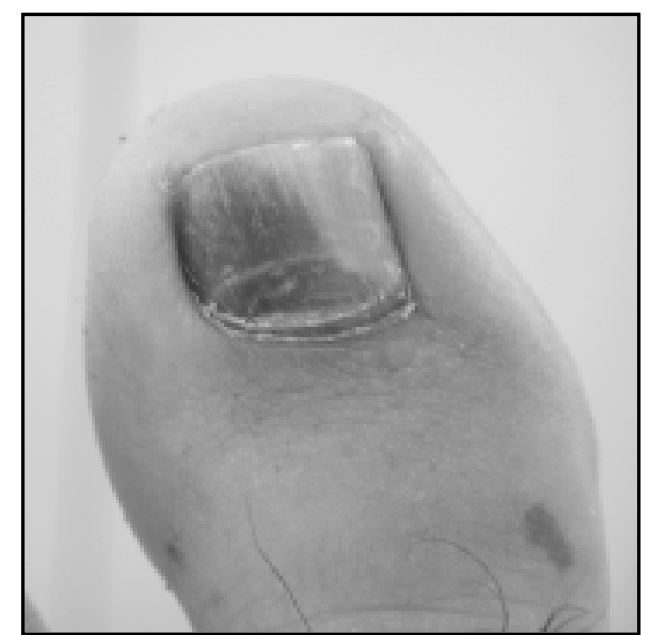

Figura 4. Hematoma subungueal primer ortejo en pie de tenista.

de vaselina y antibióticos tópicos. Se recomienda el uso de sostén en mujeres y ropa de fibras suaves como seda o telas semisintéticas. También pueden usarse bandas adhesivas protectoras 0 vaselina inmediatamente antes de correr ${ }^{1,2}$.

Estrías de distensión. Se producen por ruptura de fibras elásticas en la dermis reticular. Se disponen perpendiculares a las líneas de distensión de la piel y son más frecuentes en la región lumbar y en los muslos $^{1,2}$. No existe evidencia suficiente para recomendar un tratamiento específico y hay resultados discordantes en cuanto al efecto de la tretinoína tópica ${ }^{5,6}$ y de su combinación con ácido glicólico al $20 \%$, que ha mostrado cierto beneficio ${ }^{7}$.

Nódulos del atleta. Nódulos levemente enitematosos, asintomáticos, de $\pm 0,5 \mathrm{~cm}$ de diámetro, hiperqueratósicos, localizados en el dorso de los pies, rodillas y nudillos. Son causados por la fricción y el trauma frecuente. Histológicamente, se observa aumento de las bandas de colágeno en la dermis reticular. Frecuentes en surfistas, boxeadores y futbolistas. Algunos autores plantean que los nódulos de los surfistas comesponderían a reacciones inflamatorias a cuerpo extraño, como la arena ${ }^{1,2}$.

Uñas de golfista. Hemorragias en astilla o líneas oscuras en los dedos de las manos. Se observan en golfistas que toman el palo con mucha rigidez, produciendo exceso de presión en el lecho ungueal. Se previene tomando correctamente el palo ${ }^{1,2}$.

Palma del esquiador. Equimosis hipotenares en el borde cubital de las manos, secundario al trauma repetido con los bastones de esquí ${ }^{1}$.

Manos del remero. Lesiones vasculares subcutáneas asociadas a ampollas de fricción, que resultan por combinación de trauma mecánico y exposición al frío. Posteriormente se forman callosidades, constituyendo una ventaja deportiva ${ }^{1}$.

Pulgar de enganche. Se observan abrasiones, hematomas, ampollas de fricción, callosidades y hemorragias subungueales en pulpejo mayor de levantadores de pesas, que enganchan la barra entre pulgar, índice y dedo medio, para un mejor levantamiento del peso.

Hombro del nadador. Placa eritematosa del hombro, producida por irritación al rozar con la barba en el estilo libre ${ }^{1}$.

Glúteos de ciclista. Forma de liquen simple crónico producido por la fricción constante con el asiento. La prevención consiste en utilizar asientos acolchados y el tratamiento es con corticoides 0 inhibidores de la calcineurina tópicos ${ }^{8}$.

Glúteos de corredor. Pequeñas equimosis en la parte superior del pliegue infraglúteo producto de la constante fricción en carreras de larga distancia ${ }^{1}$.

Acné mecánico. Múltiples pápulas eritematosas y pústulas, localizadas en hombros, región occipital, mentón, pecho y rodillas, correspondiendo a zonas cubiertas por la vestimenta protectora. Entre sus causas están la presión, calor, oclusión y fricción ${ }^{9}$. Diagnóstico diferencial es con dermatitis de contacto alérgica a los materiales con los que se fabrica el equipamiento deportivo. El tratamiento es similar al de otros tipos de acné, con antibióticos tópicos y ducha inmediatamente postcompetición ${ }^{2,10}$.

Parches de ping-pong. Máculas eritematosas, redondeadas, de 2 a $3 \mathrm{~cm}$ de diámetro, causadas por el impacto de la pelota a alta velocidad en los antebrazos y el dorso de las manos ${ }^{1}$. 


\section{INFECCIONES CUTÁNEAS}

Los atletas están expuestos a infecciones de la piel y anexos debido a factores locales como humedad, sudoración, roce, fricción, contacto directo con piel infectada de otros deportistas y con superficies colonizadas (piscinas, duchas, camarines) y equipamiento deportivo que ocluye la piel, produciendo maceración y daño del estrato córneo ${ }^{2}$. Otro factor predisponente es el sobreentrenamiento que, al igual que otras formas de estrés, produce alteraciones en el sistema inmune. Además, la actitud de estoicismo de los deportistas de alto rendimiento, que prefieren soportar el dolor antes que descontinuar el entrenamiento, dificulta el diagnóstico precoz ${ }^{11}$.

\section{Infecciones virales}

Herpes gladiatorum. Infección por virus herpes simple tipo 1, que compromete a quienes practican deportes de contacto directo como lucha libre. En general las lesiones se localizan en áreas de mayor exposición como la cabeza, cara, extremidades superiores y tronco. Pueden asociarse síntomas inespecíficos como cefalea, fiebre, odinofagia, adenopatías cervicales y fatigabilidad. Se recomienda mantener a los deportistas alejados de los entrenamientos hasta que las lesiones hayan sanado totalmente ${ }^{12}$. Como profilaxis, un estudio de cohorte realizado en deportistas con herpes gladiatorum recurrente mostró supresión de nuevos episodios con el uso de Valaciclovir $500 \mathrm{mg}$ al día durante 6 meses $^{13}$.

Molusco contagioso. Producido por un Pox virus. Es más frecuente por contacto directo en quienes practican lucha libre o rugby y natación, ya que las piscinas serían una vía de diseminación del virus. La distribución de las lesiones suele obedecer a fenómeno de Koebner, y aunque tienden a desaparecer en forma espontánea en 6 a 9 meses, es necesario tratarlas para que el paciente retome su práctica deportiva ${ }^{12}$.

Verrugas plantares. Causadas por virus papiloma humano. Aunque hay un estudio que encontró mayor prevalencia de verrugas en nadadores versus no nadadores, no existen datos que atribuyan esta diferencia a la natación, sino más bien al uso de duchas comunitarias ${ }^{14}$. En cuanto a la prevención, no está demostrado que los portadores deban usar protección para no diseminar la infección en el agua ${ }^{15}$. Para no limitar la práctica deportiva, el tratamiento debe ser paulatino, reduciendo al mínimo el dolor².

Infecciones bacterianas

Impétigo. Producido por Streptococcus pyogenes o Staphylococcus aureus. Afecta principalmente a deportistas que tienen contacto directo como en la lucha libre, fútbol americano y rugby. El tratamiento es el mismo que en otros pacientes, incluyendo descostraje, antibióticos tópicos y sistémicos. Mientras el deportista esté con las lesiones activas éstas deben cubrirse para evitar el contagio con los demás miembros del equipo, o abandonar los entrenamientos hasta que hayan sanado ${ }^{2}$.

Furunculosis. Causada por S. aureus, es bastante común en deportistas. Entre los factores de riesgo se encuentran abrasiones, cortes u otras heridas; la participación en deportes de equipo que comparten áreas comunes como camarines y duchas; y la exposición a furúnculos por los demás miembros del equipo. El contacto con fomites (toallas y equipamiento deportivo) no ha demostrado ser un factor predisponente ${ }^{16}$. Aunque el diagnóstico es clínico, en ocasiones puede requerirse un cultivo bacteriológico, ya que se han descrito furunculosis por S. aureus meticilino resistente (SAMR) en equipos deportivos ${ }^{17}$. El tratamiento incluye antibióticos tópicos y sistémicos. La profilaxis con el uso de jabones antibacterianos no ha demostrado utilidad ${ }^{2}$.

Queratolisis punctata. Infección producida por Corynebacterium sp. Se observan pits crateriformes discretos, coalescentes, de 1 a $3 \mathrm{~mm}$ de diámetro, en las plantas de los pies, especialmente en las zonas de apoyo. En general tienen mal olor. El principal predisponente es la humedad, por lo que se recomienda el uso de calcetines absorbentes asociado a una solución de hidróxido de aluminio al 20\%. La infección persistente desaparece con el uso de antibióticos tópicos como eritromicina o clindamicina ${ }^{1,2}$.

Foliculitis por baño caliente. Es la principal infección por bacterias Gram negativas en deportistas. Causada por Pseudomonas aeruginosa, se presenta alre- 
dedor de $48 \mathrm{~h}$ posterior al uso de baños calientes, especialmente si la exposición es prolongada y la cloración del agua no es adecuada. Clínicamente se observan pápulas rojo-verdosas, foliculares, pruriginosas, además de vesículas y pústulas, distribuidas en la superficie corporal sumergida. Las pústulas o agua infectada deben cultivarse para confirmar el agente etiológico. Evolucionan espontáneamente en 7 a 10 días, y la recurrencia es mayor en los pacientes que han recibido tratamiento antibiótico. Por lo tanto, si no hay compromiso sistémico, el tratamiento es sólo sintomático ${ }^{2,18}$.

Oído de nadador. Otitis externa por bacterias Gram negativas como Pseudomonas sp. Los factores predisponentes incluyen maceración del conducto auditivo externo (CAE), depleción del cerumen y cambios en el $\mathrm{pH}$ por exposición al agua (Figura 5). El tratamiento consiste en suspender los entrenamientos, limpiar el canal, y aplicar una solución con antibiótico asociado a corticoide tópico. En algunos casos puede requerirse antibioterapia sistémica. El uso de ácido acético al $2 \%$ en propilenglicol parece disminuir la incidencia de infección al simular el ambiente natural del $\mathrm{CAE}^{1}$.

\section{Infecciones micóticas}

Tiña pedis. Infección micótica más frecuente en deportistas. Los factores predisponentes son: calor, ambiente húmedo del zapato y el efecto oclusivo entre sudoración, calcetines y calzado. Dentro de las fuentes de infección se encuentran duchas, camarines y piscinas. Se presentan todas las formas

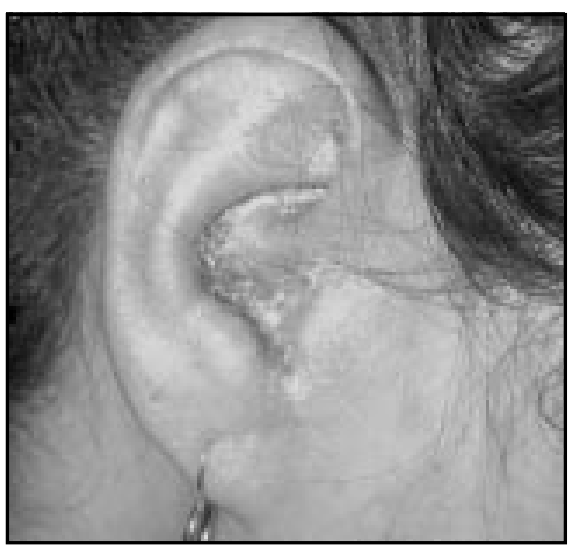

Figura 5. Otitis aguda externa por Pseudomonas aeruginosa en nadadora. clínicas, principalmente la interdigital. El tratamiento es el mismo que otros pacientes y la prevención incluye uso de calcetines absorbentes y aplicación de solución de hidróxido de aluminio al 20\%1,2.

Tiña gladiatorum. Nombre que recibe la tiña corporis que afecta a quienes practican lucha libre. Como factores de riesgo está el contacto piel con piel, sudoración, abrasiones, heridas y ropa oclusiva. Las lesiones pueden no tener el aspecto anular típico de la tiña corporis, por lo que pueden confundirse con herpes gladiatorum, impétigo 0 acné mecánico. En estos casos es útil el cultivo de hongos, encontrándose Trichophyton tonsurans ${ }^{19}$.

\section{Infecciones parasitarias}

Las infecciones por parásitos afectan generalmente a deportistas que practican en la playa o en el agua.

Larva migrans cutánea: producida por el parásito Ancylostoma, se caracteriza por placas eritematosas, serpiginosas, pruriginosas, localizadas en extremidades inferiores. El tratamiento oral con tiabendazol es efectivo ${ }^{2}$.

\section{DERMATOSIS AMBIENTALES}

Congelamiento. Congelación de piel, tejido subcutáneo, músculo e incluso hueso. Aunque puede afectar tanto áreas expuestas como no expuestas, es más frecuente en los pies y cara anterior del cuello. La respuesta fisiológica al frío es la vasoconstricción periférica que puede suceder en forma brusca cuando la temperatura es baja, manteniendo las anastomosis arteriovenosas cerradas por largo tiempo. Esto puede desencadenar trombosis intravascular, hipoxia tisular y necrosis isquémica. Además participan en el daño la hipertonicidad y deshidratación celular por congelación y la formación de cristales que alteran la membrana celular. Los nervios sensitivos dejan de funcionar a menos de $10^{\circ} \mathrm{C}$, por lo que es un síntoma ominoso el cese del dolor y la sensación de calor. Cuando hay necrosis, puede durar semanas con dolor, prurito y sudoración. El tratamiento consiste en recalentar si ya no hay riesgo de volver a congelarse, ya que la congelación repetida aumenta la necrosis tisular, como ocurre en la crioterapia. Se recomienda usar un baño entre $38^{\circ}$ y $44^{\circ} \mathrm{C}$ por $20 \mathrm{~min}$. Como 
profilaxis se recomienda el uso de varias capas de ropa, para atrapar el calor entre las capas y absorber la sudoración ${ }^{1,20-21}$.

Quemadura solar. Problema dermatológico más frecuente en quienes practican deportes al aire libre, como deportes acuáticos y de montaña, especialmente esquí. Pueden clasificarse en: quemadura de primer grado (sólo eritema), segundo grado (eritema y ampollas) y tercer grado (eritema, ampollas y ulceraciones) (Figura 6). Respecto al tratamiento, no se ha demostrado beneficio con el uso de corticoides, antiinflamatorios no esteroidales, antioxidantes, antihistamínicos y emolientes en disminuir el tiempo de recuperación ${ }^{22}$. Se recomienda enfatizar el alivio sintomático y la prevención, evitando la práctica deportiva en las horas de mayor radiación UV; usar ropa protectora liviana, y fotoprotectores resistentes al agua ${ }^{21}$. A pesar de las campañas de prevención la adherencia no es siempre óptima ${ }^{23}$.

Dermatitis de contacto alérgica. Muy frecuentes, encontrándose dentro de los alergenos los artículos deportivos de cuero, gorras de baño, anteojos de natación, pinzas nasales, tapones de oídos, zapatos con aditivos de goma o cromados, fibra de vidrio de palos de jockey, cremas tópicas con salicilatos, antibióticos, antisépticos y yodo. El tratamiento se basa en evitar el contacto con el alergeno y el uso de corticoides tópicos en la lesión aguda ${ }^{1,18}$.

Xerosis del nadador. La piel seca es muy común en nadadores debido a la dilución de la capa natural de sebo en el agua. Esto determina una

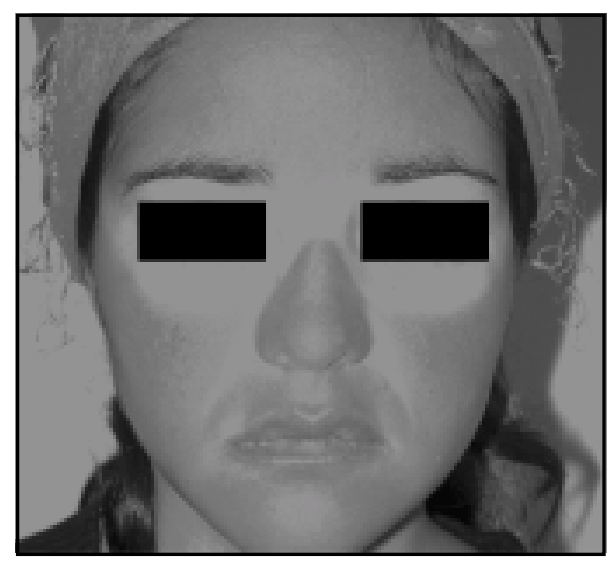

Figura 6. Quemadura solar en esquiadora. pérdida de agua en el estrato córneo, que produce piel seca, escamosa y pruriginosa. La sequedad se exacerba con baños largos de agua caliente. La prevención consiste en cambiar la ducha caliente post-entrenamiento por un enjuague rápido con agua tibia, utilizar jabón humectante y aplicar loción emoliente después del baño ${ }^{18}$.

\section{DERMATOSIS PREEXISTENTES}

Numerosas dermatosis pueden ser desencadenadas o agravadas por la práctica deportiva, ya sea por el contacto físico o por el medio donde se desarmolla.

Urticaria colinérgica. Respuesta al aumento rápido de la temperatura corporal, desencadenado por deporte, duchas calientes o estados febriles. Las ronchas son pequeñas, enitematosas, de 2 a $4 \mathrm{~mm}$ de diámetro y puede haber otros síntomas colinérgicos como lagnmeo, diarrea y sialorrea. Debuta entre los 10 y 30 años, generalmente es refractaria a tratamiento, pero puede responder a antihistamínicos ${ }^{1,24}$.

Urticaria por frío. Se presenta en deportistas de inviemo y nadadores. Se observan ronchas de diferentes tamaños en áreas expuestas al frío. El diagnóstico se confirma con la aplicación de un cubo de hielo en la piel por $5 \mathrm{~min}$, provocando formación de ronchas al recalentar la zona. Es generalmente idiopática, aunque se asocia a inmunoglobulinas dependientes del frío. El tratamiento consiste en evitar la exposición al frío, usar ropa adecuada, y antihistamínicos. Puede coexistir con urticaria colinérgica ${ }^{1,2}$.

Urticaria solar. Aparece a los pocos minutos de la exposición a la luz solar o luz UV artificial y desaparece horas después de la exposición. Se presenta inicialmente como prurito y ardor, seguido de eritema y ronchas. Las lesiones son menos frecuentes en sitios normalmente expuestos al sol como la cara y manos. La fotoprotección, el tratamiento con luz UV de longitudes de onda específica para desensibilización y PUVA terapia son efectivas ${ }^{1}$.

Anafilaxis inducida por ejercicio. Es dos veces más frecuente en mujeres y ocurre en promedio dos veces por semana. Los síntomas más frecuentes son prurito (92\%), urticaria (83\%), angioedema (78\%), síntomas respiratorios (59\%) y síncope (32\%). Tam- 
bién son frecuentes el eritema difuso, sudoración profusa y cefalea. Es común que los afectados tengan estigmas de atopía o rinitis alérgica. A diferencia de la urticaria colinérgica, la anafilaxis inducida por ejercicio puede ser de riesgo vital, por lo que es fundamental identificarla y tratarla precozmente. El edema lańngeo produce estridor inspiratonio, a diferencia del broncoespasmo de la urticaria colinérgica que produce sibilancias espiratorias. La profilaxis se basa en antihistamínicos ${ }^{1-2,24}$.

\section{REFERENCIAS}

1. Pharis DB, Teluer C, Wolf JE. Cutaneous manifestations of sports participation. J Am Acad Dermatol 1997; 36: 448-59.

2. Adams BB. Sports dermatology. Dermatology Nursing 2001; 13: 347-63.

3. KnapiK JJ, REynolds K, Barson J. Influence of antiperspirant on foot blister incidence during cross-country hiking. J Am Acad Dermatol 1998; 39: 202-6.

4. Basier R, HunzeKER CM, GarCía M. Athletic skin injuries: combating pressure and friction. Phys Sportsmed 2004; 32: 33-40.

5. ELson ML Treatment of striae distensae with topical tretinoin. J Dermatol Surg Oncol 1990; 16: 267-70.

6. Pribanich S, Simpson FG, Heid B, Yarbrough CL, White SN. Low-dose tretinoin does not improve striae distensae: a double-blind, placebo-controlled study. Cutis 1994; 54: 121-4.

7. Ash K, Lord J, Zukowski M, Mcdaniel DH. Comparison of topical therapy for striae alba (20\% glycolic acid/ $0.05 \%$ tretinoin versus $20 \%$ glycolic acid/10\% L-ascorbic acid). Dermatol Surg 1998; 24: 849-56.

8. NIEDNER R. Topical corticosteroids versus topical inhibitors of calcineurin. Hautarzt 2003; 54: 338-41.

9. BASLER RS. Acne mechanica in athletes. Cutis 1992; 50: 125-8.

10. Freiman A, Barankin B, Elpern DJ. Sports dermatology part 1: common dermatoses. CMAJ 2004; 171: 851-3.

11. BECK CK. Infectious diseases in sports. Med Sci Sports Exerc 2000; 32: 431-8.
Anafilaxis inducida por ejercicio dependiente de alimentos. Es rara, y los síntomas sólo se desencadenan cuando hubo ingesta de ciertos alimentos horas antes del ejercicio. Es fundamental la anamnesis para diferenciarla de la anafilaxis inducida por ejercicio sin asociación con alimentos. Se previene evitando ingerir alimentos 4 a $6 \mathrm{~h}$ antes del ejercicio (especialmente los que contengan proteínas de trigo), y se debe tener disponible epinefrina autoinyectable ${ }^{24}$.

12. Halstead ME, Bernhardt DT. Common infections in the young athlete. Pediatr Ann 2002; 31: 42-8.

13. ANDERSON BJ. The effectiveness of valacyclovir in preventing reactivation of herpes gladiatorum in wrestlers. Clin J Sport Med 1999; 9: 86-90.

14. JoHnson LW. Communal showers and the risk of plantar warts. Fam Pract 1995; 40: 136-8.

15. Vaile L, Fintay F, Sharma S. Should verrucas be covered while swimming? Arch Dis Child 2003; 88: 236-7.

16. Sosin DM, GunN RA, Ford WL, Skaggs JW. An outbreak of furunculosis among high school athletes. Am J Sports Med 1989; 17: 828-32.

17. Wang J, Barth S, Richardson M, Corson K, Mader J. An outbreak of Methicillin-resistant Staphylococcus aureus cutaneous infection in a saturation diving facility. Undersea Hyperb Med 2003; 30: 277-84.

18. Freiman A, Barankin B, Elpern DJ. Sports dermatology part 2: swimming and other acuatic sports. CMAJ 2004; 171: 1339-41.

19. Adams BB. Tinea corporis gladiatorum. J Am Acad Dermatol 2002; 47: 286-290.

20. FREY C. Frosbitten feet. Phys Sportsmed 1992; 20: 67-72.

21. Snowise M, DeXter W. Cold, wind, and sun exposure. Phys Sportsmed 2004; 32: 26-31.

22. Han A, Maibach HI. Management of acute sunburn. Am J Clin Dermatol 2004; 5: 39-47.

23. Boggid AK, From L. Barriers tos un safety in a Canadian outpatient population. J Cutan Med Surg 2003; 7: 292-9.

24. ADAMS ES. Identifying and controlling metabolic skin disorders. Phys Sportsmed 2004; 32: 29-40. 